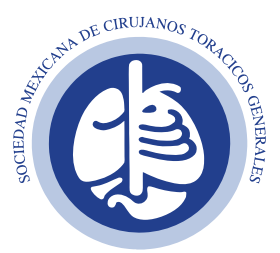

Vol. 1, Núm. 2

Mayo-Agosto 2020

pp 51-59

Palabras clave:

SARS-CoV-2, traqueostomía, cirugía de tórax.

Keywords:

SARS-CoV-2, tracheostomy, chest surgery.

* Residente de Cirugía Torácica del Instituto Nacional de Enfermedades Respiratorias (INER).

${ }^{\ddagger}$ Cirujano Torácico del Centro Médico ISSSEMYM Toluca.

$\S$ Cirujano Torácico del Institutito Nacional de Enfermedades Respiratorias (INER).

" Cirujano Torácico del Centro Médico ABC.

" Cirujano Torácico del

Hospital "Christus Muguerza"

Alta Especialidad.

** Cirujano Torácico del Hospital Cemain Tamaulipas.

㧊Cirujano Torácico

del Hospital Ángeles Metropolitano.

$\S \S$ Cirujano Torácico del

Hospital General de México.

โศ Cirujano Torácico del

Hospital General de Tijuana.

*** Cirujano Torácico

del Hospital Regional

Universitario de Colima.

执 Cirujano Torácico

del Hospital General del

Estado de Sonora.

Recibido: 21/05/2020

Aceptado: 24/06/2020

Correspondencia:

Carlos Alberto Sánchez-Soto

E-mail:

alberto8605@gmail.com
REVISTA

MEXICANA DE

CIRUGÍA

TORÁCICA

GENERAL

doi: $10.35366 / 101150$

\title{
Recomendaciones para la realización de traqueostomías y cirugía torácica durante la pandemia de SARS-CoV-2
}

\author{
Recommendations for the performance of tracheostomies \\ and thoracic surgery during the SARS-CoV-2 pandemic
}

Carlos Alberto Sánchez-Soto, ${ }^{*}$ Francisco Armas-Zárate, ${ }^{*}$

Ulises Loyola-García, ${ }^{\ddagger}$ Marco Antonio Iñiguez-García, ${ }^{\S}$ Enrique Guzmán-De Alba, "I

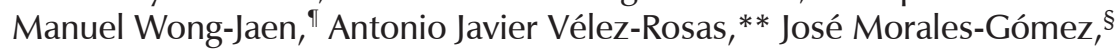

José Luis Téllez-Becerra, ${ }^{\S}$ Jorge Alberto Silva-Vivas, ${ }^{\neq \neq}$Benito Vargas-Abrego, ${ }^{\$ \S}$

Carlos Alberto Olivares-Torres, ${ }^{\text {} \uparrow\rceil ~ J e s u ́ s ~ A r m a n d o-E s t r e l l a, ~}{ }^{* * *}$ Graciano Castillo-Ortega ${ }^{\ddagger \neq \neq}$

\section{RESUMEN}

En diciembre de 2019 un grupo de pacientes en Wuhan, China, despertó el interés de las autoridades sanitarias al presentar un cuadro de neumonía atípica, lo que marcó la pauta para el descubrimiento de un nuevo virus al que la Organización Mundial de la Salud (OMS) designó como novel coronavirus 2019 (2019-nCoV) el 7 de enero de 2020. De manera rápida, el nuevo virus alcanzó la categoría de pandemia por su facilidad de transmisión a través de partículas respiratorias. El cuadro clínico incluye anorexia, odinofagia, mialgias, fiebre, tos seca y disnea. El súbito deterioro y falla respiratoria de los pacientes ha hecho que la ventilación mecánica juegue un papel vital en el tratamiento de los sujetos infectados con enfermedad grave, a pesar de la intubación prolongada, debe considerarse a los pacientes infectados de SARS-CoV-2 como población especial, por ello, la realización de traqueostomías tiene consideraciones especiales. Este trabajo resalta la importancia de preservar la seguridad de los equipos médicos especializados que continúan laborando en la atención de estos pacientes. Debe hacerse un esfuerzo mayor para minimizar los contagios y fallecimientos del personal de salud. La Sociedad Mexicana de Cirujanos Torácicos Generales (SMCTG) realizó una revisión de la evidencia científica disponible para emitir las siguientes recomendaciones de seguridad a quienes realizan procedimientos quirúrgicos en pacientes con SARS-CoV-2.

\section{ABSTRACT}

In December 2019, a group of patients in Wuhan, China, aroused the interest of health authorities by presenting a picture of atypical pneumonia, setting the stage for the discovery of a new virus that the World Health Organization (WHO) designated as novel coronavirus 2019 (2019-nCoV) on January 7, 2020. The new virus quickly reached pandemic status because of its ease of transmission through respiratory particles. The clinical presentation includes anorexia, odinophagia, myalgia, fever, dry cough and dyspnea. The sudden deterioration and respiratory failure of patients has made mechanical ventilation play a vital role in the treatment of severely ill patients, despite prolonged intubation, SARS-CoV-2 infected patients should be considered as a special population, so the performance of tracheostomies has special considerations. This work highlights the importance of preserving the safety of the specialized medical teams that continue to work in the care of these patients. A greater effort should be made to minimize the number of infections and deaths among health care workers. The SMCTC conducted a review of the available scientific evidence to issue the following safety recommendations to those performing surgical procedures on patients with SARS-CoV-2.

Citar como: Sánchez-Soto CA, Armas-Zárate F, Loyola-García U, Iñiguez-García MA, Guzmán-De Alba E, Wong-Jaen M et al. Recomendaciones para la realización de traqueostomías y cirugía torácica durante la pandemia de SARS-CoV-2. Rev Mex Cir Torac Gen. 2020; 1(2): 51-59. https://dx.doi.org/10.35366/101150 


\section{INTRODUCCIÓN}

El contagio de SARS-CoV-2 ocurre tras el contacto físico, la inhalación o la absorción por las mucosas de gotas y aerosoles de individuos infectados. ${ }^{1,2}$

Una vez descifrado el genoma del virus, se identificó una similitud de $86.9 \%$ al genoma del SARS-CoV (severe acute respiratory syndrome coronavirus), esto modificó su denominación a SARS-CoV-2. 3,4

Una de las prioridades de la OMS es limitar la transmisión entre trabajadores de la salud; aunque tanto el SARS como el SARS-CoV-2 se transmiten mediante aerosoles, se sabe que la infectividad y el alcance del SARS-CoV-2 es superior al del SARS-CoV en $2003 .^{5}$

La capacidad de transmisión del virus la determina el número básico de reproducción (r0), éste representa la cantidad de personas que se pueden infectar a partir de una persona positiva cuando $\mathrm{r} 0$ es mayor de 1 , la enfermedad se contagia exponencialmente con la capacidad de generar una pandemia. El 23 de enero de 2020, la OMS presentó un estimado del r0 para el SARS-CoV-2 de 1.4 a 2.5, mientras que para el SARS-CoV en 2002 se estimó un r0 de 0.8 . Por este comportamiento de alto contagio, las medidas preventivas para mantener seguro al personal médico son primordiales. ${ }^{6-8}$

De acuerdo al comunicado técnico diario realizado por la Secretaría de Salud, el 22 de mayo de 2020, en México, existían 62,527 casos confirmados y 6,989 muertes por SARS-CoV-2.

Debido a la necesidad de realizar intervenciones quirúrgicas en pacientes sospechosos o confirmados de SARS-CoV- $2,{ }^{5}$ la Sociedad Mexicana de Cirujanos Torácicos Generales (SMCTG), basándose en la evidencia científica disponible hasta este momento, pone a disposición las siguientes recomendaciones.

\section{Recomendaciones generales}

El lunes 30 de marzo el Consejo de Salubridad General declaró, en la edición vespertina del Diario Oficial de la Federación (DOF), la emergencia sanitaria por causa de fuerza mayor a la epidemia causada por el virus SARS-CoV-2 (COVID-19).

\section{Quirófano y personal}

Efectuar procedimientos quirúrgicos es un evento de riesgo tanto para el paciente como para el equipo médico-quirúrgico. La infección con SARS-CoV-2 de todo un equipo quirúrgico puede ser catastrófica no sólo para el paciente sino también para el hospital, e incluso para la población que es atendida por la especialidad médica.

\section{Equipo quirúrgico}

A. Evaluación de riesgo de contagio/realización de prueba para SARS-CoV-2: cuando algún miembro del equipo ha sido contagiado de SARS-CoV-2 y se ha recuperado completamente puede considerarse integrarlo al equipo de alto riesgo. De contarse con ello, todo el personal debería realizarse la prueba molecular para conocer su estado. ${ }^{4}$

B. Equipo quirúrgico frío y caliente (bajo riesgo VS. alto riesgo): asignar un quirófano y personal para procedimientos de alto y bajo riesgo reduce las posibilidades de infección. El equipo de alto riesgo atiende a aquellos pacientes sospechosos o confirmados de SARS-CoV-2 y el de bajo riesgo a aquellos que han sido descartados y son negativos. Idealmente el equipo caliente deberá ser provisto de mayores medidas de protección como presión negativa. ${ }^{4}$ Los quirófanos que no cuenten con presión negativa no deben utilizar el aire acondicionado, debido a la generación de aerosoles. Además, debe asignarse a un monitor que vigile el proceso de vestido y desvestido del equipo de protección personal (EPP).

C. Personal mínimo indispensable y con mayor destreza durante el procedimiento: la mayor habilidad técnica reduce tiempos de exposición, el menor número de involucrados disminuye la posibilidad de contagio del personal y aumenta la eficiencia de la utilización de los equipos de protección personal. Las turbulencias en el flujo de aire son mayores conforme aumenta el número de personas en la sala. Se recomienda que los cirujanos con mayor experiencia realicen los procedimientos, se debe evitar exponer a estudiantes o a personal en entrenamiento.

D. Sistema de succión/extracción de vapores/uso de bipolar: todo sistema de electrocirugía genera humo, éste debe ser reducido al mínimo para evitar la generación de aerosoles. De estar disponibles la diatermia bipolar con succión y/o extractores deben ser utilizados. El uso de bipolar genera menos 
humo. Los sistemas de succión deben ser cerrados y contar con filtro viral. ${ }^{4}$

E. Anestesiología: intubación/extubación orotraqueal al interior de quirófano. La ventilación con bolsaválvula-mascarilla, ventilación mecánica e intubación con el paciente despierto pueden generar más aerosoles con riesgo de transmisión por partículas aéreas en los involucrados en el procedimiento. Se sugiere el uso de sistemas de contención de aerosoles, los cuales ofrecen una mayor barrera de protección al manipular la vía aérea, la caja se ha adaptado con puertos laterales para la realización de traqueostomía y la realización de cirugía aerodigestiva. ${ }^{4}$

\section{Equipo de protección personal (EPP)}

Durante el brote de SARS-CoV en 2003, Hong Kong, Canadá y Singapur utilizaron equipo reforzado de protección que iba desde caretas faciales hasta respiración autónoma para la realización de sus traqueostomías; los 23 integrantes de los diferentes equipos permanecieron libres de contagio. ${ }^{1,5}$

Mientras que en el reciente brote de SARS-CoV-2, el ministerio de salud en China reportó 3,300 miembros del sistema de salud infectados y 22 murieron; Italia reportó más de 5,000 médicos, enfermeras, técnicos y otros empleados del área de salud infectados y dentro de este grupo 41 fallecieron, la mayoría en el punto de mayor actividad relacionada al SARS-CoV-2. El suministro oportuno del EPP con los requerimientos internacionales y la capacitación para su correcto uso son esenciales durante la pandemia de SARS-CoV-2. ${ }^{1}$

Por otro lado, se pueden categorizar dos tipos de pacientes: el primero, de bajo riesgo (PBR) sin historia clínica, de laboratorio o síntomas relacionados a SARSCoV-2; el segundo, de alto riesgo (PAR), aquéllos que requieren una cirugía de emergencia desconociendo su serología SARS-CoV-2, los que cuenten con una prueba positiva, síntomas o antecedentes clínicos de exposición a SARS-CoV-2.1,2,5

EPP en pacientes de bajo riesgo:

- Doble par de guantes.

- Mascarilla FFP3 (N99) o P3 (N100), deben contar con sello de certificación (NIOSH o FFP).

- Botas impermeables.
- Gorro quirúrgico.

- Bata impermeable.

- Gafas protectoras/careta

EPP en pacientes de alto riesgo:

- EPP estándar; la bata puede sustituirse por overol.

- Bata quirúrgica impermeable/mandil impermeable sobre bata no impermeable.

- Supervisión para vestido y retiro del EPP.

Aunque la disponibilidad del equipo de protección personal puede variar de institución en institución, el EPP estándar es el mínimo requerido para seguridad del personal. Los procedimientos generadores de aerosoles tales como intubación orotraqueal, broncoscopia, traqueostomía, desconexión del circuito de ventilación y resucitación cardiopulmonar pueden requerir medidas adicionales de protección si están disponibles, tales como purificadores de aire, trajes cerrados con presión positiva o purificadores, etcétera. Las mascarillas deben tener el sello de certificación americano (NIOSH) o europeo (FFP). ${ }^{9}$

Cualquier procedimiento quirúrgico debería realizarse con el EPP mínimo recomendado (gorro, gafas protectoras o careta, respirador N95 o superior, bata impermeable u overol, cubrezapatos o botas impermeables y guantes), y en pacientes de alto riesgo se tomarán medidas adicionales. La instauración de medidas de protección deben ser agresivas, incluso en centros no destinados para la atención de pacientes SARS-CoV-2. Mediante modelos estadísticos se estimó una transmisión por pacientes asintomáticos de $17.9 \%$, pero el estudio realizado en el brote al interior del crucero Diamond Princess arrojó que hasta $46.5 \%$ de los contagios se pudieron haber originado a través de personas sin datos clínicos. ${ }^{10}$

Los virus SARS y SARS-CoV-2 son similares en tamaño, ambos de aproximadamente $85 \mathrm{~nm}$, las partículas de virus pueden penetrar cinco cubrebocas quirúrgicos estándar colocados uno sobre otro, por lo que se debe proveer al personal de salud con mascarillas N95 o superior. El uso de estas mascarillas reducen la penetración de partículas virales de entre 10 y $80 \mathrm{~nm}$ hasta en 95\%.2,11

\section{Sala de operaciones}

Los procedimientos deben realizarse, de manera ideal, en quirófano, con luz, materiales y espacio adecuados. 
Como alternativa se puede adaptar temporalmente un quirófano en la Unidad de Cuidados Intensivos (UCI), los dos anteriores empleando presión negativa, idealmente. Sólo si los anteriores no están disponibles, se debe adaptar un cubículo completamente aislado en la UCI.

Los sistemas de succión de preferencia deben ser cerrados y contar con un sistema de filtrado de alta eficiencia (filtros virales) y presión negativa continua.

\section{CIRUGÍA DE EMERGENCIA}

Como cualquier población, los pacientes SARS-CoV-2 pueden presentar una serie de padecimientos quirúrgicos además del cuadro respiratorio. Se debe contar con un protocolo hospitalario que no exponga a otros pacientes o al personal a un posible contagio cuando se transfieran pacientes SARS-CoV-2 positivos o sospechosos de pabellones y áreas de terapia intensiva al quirófano. El tránsito en pasillos y uso de elevadores debe ser una maniobra muy bien coordinada en la movilización para evitar tiempos muertos en tránsito, como la espera de ascensores o puertas. 2,6,12

De manera ideal el quirófano designado para pacientes SARS-CoV-2 debe estar completamente equipado, disminuir el movimiento del personal es prioridad, los circulantes deben estar fuera del quirófano, y a través de un traspaso en dicha sala de operaciones se hará la entrega de material. 2,12

Todo paciente que requiera un procedimiento torácico de emergencia debe ser valorado por la posibilidad de estar infectado con SARS-CoV-2, aun si es asintomático, se recomienda: ${ }^{2}$

- Evaluación de riesgo de infección/realización de prueba.

- Radiografía de tórax o tomografía de tórax.

- Cada cirugía representa un riesgo para el paciente y para el equipo.

Debe considerarse que una prueba PCR de muestra nasofaríngea negativa para SARS-CoV-2, no descarta que el individuo esté infectado; 8 de 10 pacientes pediátricos con prueba respiratoria repetidamente negativa tuvieron prueba positiva en hisopados rectales de acuerdo con una publicación china. ${ }^{13}$

Se estima una sensibilidad de las pruebas de PCR de $83.3 \%$ cuando la muestra es nasal o faríngea; las muestras de tracto respiratorio inferior son más difíciles y riesgosas de obtener. ${ }^{14}$

Cada procedimiento quirúrgico, incluyendo invasión mínima o endoscopias, conlleva un riesgo elevado para el paciente y el personal de salud, por lo que deben tomarse todas las medidas de protección. ${ }^{2}$

\section{TRAQUEOSTOMÍA}

Los pacientes con intubación prolongada requieren un manejo más seguro de la vía aérea, para ello se recurre a la traqueostomía; sin embargo, debemos reiterar que se trata de un procedimiento de alto riesgo al ser generador de aerosoles. Por ello, el equipo quirúrgico tiene mayor riesgo de contagio.

Es previsible que se incremente la solicitud de traqueostomías, pero la decisión de realizarla jamás debe ser tomada a la ligera y debe insistirse en que la limitación de equipos de protección personal o su uso inadecuado pueden representar un riesgo muy alto para el personal proveedor de salud. ${ }^{15}$

El déficit de ventiladores y camas de cuidados intensivos se ha observado en todos los países por el incremento rápido de casos con SARS-CoV-2. Acortar la estancia en la $\mathrm{UCl}$ y reducir el número de pacientes que requieren ventilación mecánica es de vital importancia. ${ }^{16}$

El pronóstico de los pacientes SARS-CoV-2 en ventilación mecánica es malo. Una serie de 52 pacientes críticamente enfermos comparó a los sobrevivientes VS. Ios fallecidos; 30 (81\%) de 37 pacientes que requirieron ventilación mecánica habían fallecido a los 28 días. Tres pacientes intubados de los sobrevivientes permanecieron intubados a los 28 días. ${ }^{17}$

En otra serie en Wuhan, con 101 pacientes sobrevivientes, la intubación media fue de cinco días con rango intercuartil de dos a ocho días (mínimo 1, máximo 31 días). En este estudio surge la duda de si esos pacientes con ventilación prolongada se hubieran beneficiado de una traqueostomía. ${ }^{18}$

Debe enfatizarse que el riesgo de infección del personal que realizó traqueostomías en el brote de SARS en 2002 obtuvo un OR de 4.15 (IC 95\% 1.205.8; $\mathrm{p}<0.005){ }^{16,19}$

Al determinar la realización de una traqueostomía debe decidirse cada caso de forma individual; no existe evidencia sustancial respecto al mejor tiempo para su realización. La indicación de una traqueosto- 
mía sigue siendo ofrecer mejor ventilación mecánica al paciente y disminuir las complicaciones por tubos endotraqueales, pero con el inconveniente de ser un riesgo de contagio para el personal que realiza el procedimiento.

\section{Consideraciones de traqueostomía en pacientes con SARS-CoV-2:5,15,16,20}

A. Las traqueostomías deben realizarse con bloqueo neuromuscular, independientemente de la técnica. No hay evidencia suficiente de superioridad para realizar traqueostomías quirúrgicas, percutáneas con dilatación (PD) o mixtas.

B. Existe controversia en cuanto al momento para realizar una traqueostomía; se ha descrito que en pacientes con intubación por más de 21 días, sin otras comorbilidades y con buena evolución clínica puede ofrecer algún beneficio. Una publicación reciente en The Lancet sugiere que se realice después del día 10 siempre y cuando haya mejoría clínica evidente.

a. Debe sesionarse con el equipo médico, quirúrgico, cuidados paliativos y familia el pronóstico del paciente y determinar si el beneficio supera al riesgo de contagio.

b. Se sugiere establecer un equipo único que realice las traqueostomías en pacientes SARS-CoV-2 y disminuir la exposición de múltiples miembros del equipo.

C. La Sociedad de Canadiense de Cirugía de Cabeza y Cuello no recomienda la realización de traqueostomías en pacientes con infección activa y sólo la consideran si el tubo endotraqueal es insuficiente para ventilar al paciente.

D. Cuando se considere realizar una traqueostomía en paciente positivo, se debe considerar el uso de EPP con respiradores purificadores de aire (PAPR).

E. Casos especiales deben sesionarse con el equipo multidisciplinario, por ejemplo vía aérea difícil.

\section{Generalidades}

Una vez designada la realización de la traqueostomía deben considerarse los siguientes aspectos: ${ }^{5,15,16}$
A. Es recomendable realizar traqueostomía quirúrgica cuando no se tiene el equipo o experiencia adecuados en otras técnicas. Los procedimientos abiertos ofrecen la visión directa de la vía aérea y control absoluto durante su apertura. Los cirujanos con más experiencia pueden realizar el procedimiento de manera rápida.

B. Si se cuenta con la suficiente experiencia y el material adecuado (broncoscopio desechable por paciente, equipos de dilatación, succión cerrada con filtros virales, EPP con PAPR) puede considerarse la técnica percutánea, teniendo en cuenta que la manipulación del broncoscopio o la pérdida accidental de la guía de dilatación puede representar un mayor riesgo de formación de aerosoles.

C. Puede considerarse traqueostomía PD si la anatomía del paciente es favorable y se tienen la experiencia y los recursos disponibles; aun así, la guía visual broncoscópica puede aumentar la generación de aerosoles a través del puerto de broncoscopia y representa un riesgo mayor de contagio.

D. Realizar el procedimiento idealmente en un cubículo que cuente con presión negativa, de lo contrario realizarlo en el quirófano asignado para este fin y que de manera óptima también debiera tener presión negativa.

E. Personal: personal mínimo pero con la mayor experiencia posible en la sala. Es muy importante reducir la exposición de la mayor cantidad de personal posible.

a. Se recomienda que la traqueostomía abierta se realice por dos cirujanos expertos y un anestesiólogo en estrecha comunicación.

b. La traqueostomía PD puede realizarse por un solo cirujano, si no se utilizará guía visual endoscópica, y un anestesiólogo.

c. En traqueostomía PD con visión por broncoscopia, el equipo será de tres al igual que en las traqueostomías abiertas.

F. Equipo de protección. La traqueostomía se considera generadora de aerosoles, se deben tener precauciones por gotas y partículas aéreas. Debe utilizarse el EPP estándar y bata quirúrgica estéril. En los centros que se disponga de equipos con purificador de aire deben considerar su uso. 
G. El equipo estándar consta de máscara N95 o superior, gafas protectoras y/o careta, gorro quirúrgico y bata impermeable, además se debe utilizar la bata quirúrgica estéril. En centros que dispongan de trajes cerrados completos (overol) se debe considerar su uso.

\section{Traqueostomía abierta}

Todo procedimiento requiere estrecha comunicación con el equipo que estará a cargo de la vía aérea, no deben realizarse maniobras sin previa notificación y confirmación por el equipo involucrado. ${ }^{15,16}$

- Paciente con bloqueo neuromuscular completo.

- Equipo de corte electroquirúrgico con succión a sistema cerrado.

- El balón del tubo endotraqueal localizado distal al sitio de traqueotomía debe verificarse mediante palpación.

- Verificar instrumentos, correcto tamaño y funcionamiento de cánula antes de traqueotomía.

- Para la apertura de la tráquea debe coordinarse con anestesiología la apnea del paciente y evitar cualquier modo ventilatorio que ejerza presión con equipo de anestesia (CPAP, PEEP).

- La guía inglesa y las recomendaciones emitidas por la Universidad de Pensilvania respecto a traqueostomías en pacientes con SARS-CoV-2, sugieren realizar una ventana traqueal (FLAP de Björk).

- Se debe introducir la cánula de forma precisa y rápida, siempre verificar balón inflado antes de restituir la ventilación mecánica.

\section{Traqueostomía percutánea con dilatación (TPD)}

Al igual que las traqueostomías abiertas, la apertura de la vía aérea debe estar estrechamente coordinada con el anestesiólogo. Se han descrito recientes modificaciones a la técnica de traqueostomías percutáneas como la serie efectuada publicada por el Dr. Cerfolio que incluyó 98 procedimientos percutáneos de 270 pacientes con ventilación mecánica. El personal involucrado en los 98 procedimientos se realizó pruebas PCR de hisopado nasofaríngeo, los cuales fueron negativos. ${ }^{15,16,21,22}$

- Paciente con bloqueo neuromuscular.

- Se sugiere la utilización de un kit de broncoscopio y set de dilatación desechables por paciente.
- Las guías de la Universidad de Pensilvania para la realización de traqueostomía PD recomienda no usar guía broncoscópica cuando la anatomía del paciente es favorable y se cuenta con la experiencia suficiente.

- Si se usa broncoscopio, la introducción del mismo debe realizarse en apnea, y se recomiendan medidas para disminuir aerosoles como una cánula Yankauer o una gasa en la cavidad orofaríngea durante el procedimiento.

- Una vez confirmado el funcionamiento del equipo, se procede con la apnea del paciente, se desinfla parcialmente el globo del tubo endotraqueal y se extrae hasta observar claramente el sitio de punción, reinflar el balón antes de restaurar la ventilación.

- Una vez hecha la punción la guía metálica debe cubrirse alrededor con gasas en cada cambio de dilatador para minimizar la dispersión de aerosoles.

- El intercambio de dilatadores debe minimizarse o utilizar equipos con dilatador único progresivo.

- Verificar que la cánula está en vía aérea, inflar el balón.

- No se debe reiniciar la ventilación hasta comprobar lo anterior.

\section{Cuidados postraqueostomía}

Paciente con ventilación mecánica:16,21

- El circuito del ventilador debe incluir un filtro viral.

- Utilizar succión de circuito cerrado.

- Las endocánulas no deben limpiarse y reutilizarse. Deben desecharse.

- Las recomendaciones de Reino Unido y de la Universidad de Pensilvania mencionan revisar periódicamente la presión del balón de la cánula.

- No realizar cambio de gasas a menos que se observen francamente sucias.

Pacientes sin ventilación mecánica: ${ }^{16,21}$

- Aun después del destete del ventilador, el paciente debe utilizar un sistema cerrado como un intercambiador de calor-humedad con un filtro viral. Esto disminuye la posibilidad de dispersión de aerosoles del paciente.

- No se recomienda el uso de collar traqueal.

- Sólo aspirar si es indispensable, debe realizarse con circuito cerrado de succión. 
- El cambio de cánula debe realizarse sólo hasta que el paciente no sea infeccioso.

\section{CIRUGIIA ONCOLÓGICA TORÁCICA DURANTE PANDEMIA SARS-CoV-2}

La demanda acelerada de recursos materiales y humanos por la pandemia de SARS-CoV-2 ha alterado la manera de brindar atención a pacientes con malignidades torácicas. La viabilidad de los procedimientos quirúrgicos se ha restringido de forma importante en diversas regiones. Diferir la realización de una cirugía oncológica tiene implicaciones en la supervivencia de los pacientes o en la disminución de su calidad de vida. Debe considerarse que los pacientes con patología torácica son de alto riesgo por el compromiso de su función respiratoria y cardíaca. ${ }^{23}$

La cirugía oncológica es una de las actividades que no pueden suspenderse durante la pandemia de SARSCoV-2 apegados a los lineamientos de reconversión hospitalaria de la secretaría de salud. ${ }^{18}$

Estos padecimientos tienen prioridad y se recomienda la realización de las cirugías en un centro libre de pacientes con SARS-CoV-2 con una estratificación dependiendo de la urgencia de la cirugía. Algunos centros han establecido protocolos para la evaluación del riesgo a pacientes que no son sospechosos de SARSCoV-2 y que serán sometidos electivamente a cirugía oncológica. Se incluyen cuestionarios, realización de prueba molecular o tomografía y si se encuentra alguna anormalidad el paciente se cataloga como sospechoso y se difiere el procedimiento. ${ }^{11,12,20,23,24}$

Los hospitales receptores de pacientes con patología oncológica torácica deberían integrar un comité para discutir los casos de manera individual considerando lo siguiente:

- El comportamiento tumoral (histología, invasión, cinética).

- Limitación de recursos en áreas de oncología médica, quirúrgica o radiooncología, varía en cada centro.

- Reducir y restringir el número de pacientes en atención al distanciamiento físico.

El seguimiento de los pacientes a quienes se haya diferido un procedimiento será según su patología:
- Reestadificación, ser selectivo, pues los servicios de radiodiagnóstico estarán limitados.

- Los pacientes en quienes mayor retraso comprometa su función o la vida deben ser priorizados al reiniciar los procedimientos.

- Deben considerarse tratamientos alternativos mientras se realiza la cirugía (stents, quimioterapia, ablación, radioterapia).

Los pacientes con tumores pulmonares de células no pequeñas resecables, los tumores esofágicos y de unión esofagogástrica preferentemente deben ser valorados antes de un mes del diferimiento inicial. ${ }^{24}$

\section{NEUMOTÓRAX}

Durante el brote de SARS-CoV, en la revista CHEST se publicó una serie de casos de neumotórax espontáneos que ocurrieron en seis de 356 pacientes hospitalizados en Hong Kong, lo que representaba una incidencia de $1.7 \%$. En esos pacientes el neumotórax fue bilateral y dos murieron. Los cuatro pacientes restantes desarrollaron neumotórax recurrentes y fuga aérea con media de 23.5 días para su resolución. A pesar de las indicaciones quirúrgicas (neumotórax bilateral y fuga prolongada), los pacientes se manejaron de forma expectante. Una de las razones para evitar cirugías en esos pacientes era disminuir el riesgo de contagio entre el personal médico. En aquel brote 30\% de los pacientes infectados pertenecían al gremio médico. ${ }^{19}$

\section{DRENAJES PLEURALES Y RIESGO DE AEROSOLES}

Los pacientes con SARS-CoV-2 pueden desarrollar derrame pleural o neumotórax, lo cual requiere la colocación de sondas pleurales. No se ha establecido cuan elevado es el riesgo de contagio por aerosoles durante la colocación de un drenaje. En pacientes con una fuga aérea este riesgo podría incrementarse. Las sondas endopleurales pueden ser un medio de transmisión subreconocido. ${ }^{25}$

Los sistemas de drenaje pleural incluyen un puerto para conectar la succión de baja presión de la pared; los sellos más modernos tienen una válvula de seguridad para evitar un neumotórax a tensión en caso de desconexión accidental de la succión. El burbujeo en el sello pleural puede generar aerosoles que escapen del sello a través de las válvulas o puertos. ${ }^{25}$ 
Hasta que no se determine el volumen de aerosoles que pueden fugarse por un sello pleural, se recomienda la utilización de sistemas de succión cerrado y la interposición de un filtro viral con extensión previo al puerto de succión; la extensión en el puerto y luego el filtro son para evitar que éste se humedezca, ya que puede disminuir su eficiencia (Figura 1). Dada la emergencia del SARS-CoV-2 cualquier método que disminuya la posibilidad de dispersión del virus debe considerarse, aunque en el futuro deben realizarse estudios que aporten evidencia más sustentada. ${ }^{25}$

\section{OTROS PROCEDIMIENTOS ELECTIVOS}

La realización de cirugías electivas debe suspenderse en los centros designados para atención de pacientes SARS-CoV-2; estos pacientes deben redirigirse a las instituciones designadas y debe darse prioridad a procedimientos oncológicos. Reducir los procedimientos quirúrgicos electivos tiene tres ventajas: ${ }^{1,12}$

1. Liberación de camas disponibles en pabellones generales y terapia intensiva; las áreas de recuperación pueden ser convertidas a terapia intensiva de forma temporal, esto incrementa la capacidad de atención a pacientes con SARS-CoV-2.

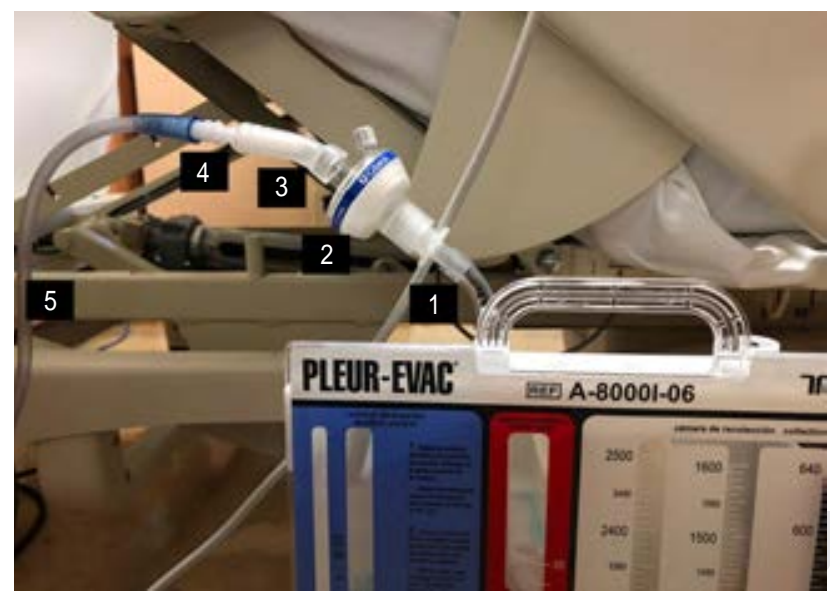

Figura 1: Sello pleural con filtro viral (Humid-Vent ${ }^{\circledR}$ Filter Compact) añadido en puerto de succión. (Con Autorización del Dr. Enrique Guzmán de Alba-Centro Médico ABC, México.) (1) Extensión con fragmento de tubo traqueal Rusch 8.5 en puerto de succión. (2) Filtro Viral-Bacterial (Humid-Vent ${ }^{\circledR}$ Filter Compact), eficiencia 99.999\%. (3) Extensión con fragmento de tubo de silicón. (4) Conector de Sims. (5) Succión.
2. Pone personal a disposición; los anestesiólogos y cirujanos con entrenamiento en cuidados críticos puede apoyar en la atención médica mientras que los cirujanos sin entrenamiento pueden cubrir situaciones de emergencia.

3. Reduce el riesgo de infección cruzada a pacientes electivos, visitantes y personal médico bajando la tasa de dispersión en la comunidad.

Todo paciente a quien se le vaya a realizar procedimientos electivos considerar lo siguiente:

- Evaluar el riesgo de paciente positivo asintomático/ realizar prueba molecular.

- Prueba de caminata o reto de ascenso de escaleras y gasometría arterial.

- De ser posible diferir el procedimiento.

El presidente del Instituto Robert Koch, sugirió posponer todas las intervenciones. La cirugía por sí misma se considera un evento riesgoso para el paciente y el personal de salud, se ha observado que puede desencadenar eventos potencialmente fatales en aquellos en quienes se realiza el diagnóstico tardíamente. En pacientes con SARS-CoV-2 es un evento más que aventurado someterse a cirugía. ${ }^{2}$

\section{COMPLICACIONES QUIRÚRGICAS EN PACIENTES SARS-CoV-2}

En hospitales no designados para pacientes SARS-CoV-2, la presencia de fiebre y síntomas respiratorios en un paciente posoperado deben levantar sospechas de una posible infección. El paciente debe aislarse y realizar el protocolo de estudio hasta descartarse la infección.

Los hospitales o nosocomios con población SARSCoV-2 positivos deben tener en cuenta que el deterioro respiratorio puede ser rápido y se debe estar pendiente de la evolución. Una vez que el paciente esté listo para egresar deben ser consideradas las necesidades psicosociales y dar indicaciones muy claras respecto a su aislamiento en casa y los datos de alarma por los que debe acudir nuevamente al hospital.2,12

\section{CONSIDERACIONES ÉTICAS}

Involucrarse en el tratamiento de un paciente con infección activa de SARS-CoV-2 genera en ocasiones 
un dilema. El riesgo para el personal de salud y el beneficio posible que el paciente puede obtener de dicha cirugía deben discutirse en cada evento. Deben tomarse las medidas necesarias para optimizar el tratamiento de los pacientes sin exponer innecesariamente al personal. Cuando se cuente con múltiples opciones de tratamiento con resultados previsibles similares se debe elegir la menos riesgosa.

\section{CONCLUSIONES}

La pandemia de SARS-CoV-2 ha modificado la dinámica hospitalaria a todos los niveles y representa además un riesgo infectocontagioso para el personal de salud. Debe considerarse la seguridad del personal médico como prioritaria, por lo cual es importante discutir de forma multidisciplinaria cada evento.

La realización de traqueostomías debe ser un procedimiento rápido y con la menor exposición de personal posible. La técnica abierta por su seguridad y rapidez se recomienda en diversos centros del mundo; si se cuenta con el equipo y experiencia necesarios, puede considerarse la realización de traqueostomías percutáneas con dilatación. Cada caso debe discutirse de forma individual debido al alto riesgo que representa para el paciente y el equipo médico.

Se recomienda que la cirugía electiva se derive a un centro libre de casos sospechosos o confirmados de SARS-CoV-2 y en ningún momento debe pasarse por alto que aun los pacientes asintomáticos pueden estar infectados. La cirugía oncológica se considera prioritaria siempre que se haya descartado la infección SARS-CoV-2.

Proveer de EPP que cumpla con las certificaciones internacionales es indispensable. El personal médico involucrado en la atención de pacientes debe utilizar en todo momento su EPP de forma adecuada.

\section{REFERENCIAS}

1. Udwadia ZF, Raju RS. How to protect the protectors: 10 lessons to learn for doctors fighting the COVID-19 coronavirus. Med J Armed Forces India. 2020; 76(2): 128-131.

2. Brücher BL, Nigri G, Tinelli A, Lapeña JFF, Espin-Basany E, Macri P et al. COVID-19: Pandemic surgery guidance. 4open. 2020; 3: 1.

3. NaserChandi A, Allameh SF, Saffarpour R. All about COVID-19 in brief. New Microbes New Infect. 2020; 35: 100678.
4. Ozma MA, Maroufi P, Khodadadi E et al. Clinical manifestation, diagnosis, prevention and control of SARS-CoV-2 (COVID-19) during the outbreak period. Infez Med. 2020; 28(2): 153-165.

5. Tay JK, Khoo ML, Loh WS. Surgical considerations for tracheostomy during the COVID-19 pandemic: lessons learned from the severe acute respiratory syndrome outbreak. JAMA Otolaryngol Head Neck Surg. 2020.

6. Coccolini F, Perrone G, Chiarugi M et al. Surgery in COVID-19 patients: operational directives. World J Emerg Surg. 2020; 15(1): 25.

7. Lee CH. Disaster and mass casualty triage. Virtual Mentor. 2010; 12(6): 466-470.

8. Chen J. Pathogenicity and transmissibility of 2019-nCoV-A quick overview and comparison with other emerging viruses. Microbes Infect. 2020; 22(2): 69-71.

9. Alhazzani W, Møller MH, Arabi YM et al. Surviving Sepsis Campaign: guidelines on the management of critically ill adults with Coronavirus Disease 2019 (COVID-19). Intensive Care Med. 2020; 46(5): 854-887.

10. Moriarty LF, Plucinski MM, Marston BJ et al. Public health responses to COVID-19 outbreaks on cruise ships-worldwide, February-March 2020. MMWR Morb Mortal Wkly Rep. 2020; 69(12): 347-352.

11. Bałazy A, Toivola M, Adhikari A, Sivasubramani SK, Reponen T, Grinshpun SA. Do N95 respirators provide 95\% protection level against airborne viruses, and how adequate are surgical masks? Am J Infect Control. 2006; 34(2): 51-57.

12. COVIDSurg Collaborative. Global guidance for surgical care during the COVID-19 pandemic. Br J Surg. 2020.

13. $\mathrm{Xu}$ Y, Li X, Zhu B et al. Characteristics of pediatric SARS-CoV-2 infection and potential evidence for persistent fecal viral shedding. Nat Med. 2020; 26(4): 502-505.

14. Long $\mathrm{C}, \mathrm{Xu} \mathrm{H}$, Shen Q et al. Diagnosis of the Coronavirus disease (COVID-19): rRT-PCR or CT? Eur J Radiol. 2020; 126: 108961.

15. Pichi B, Mazzola F, Bonsembiante A et al. CORONA-steps for tracheotomy in COVID-19 patients: A staff-safe method for airway management. Oral Oncol. 2020; 105: 104682.

16. Chao TN, Braslow BM, Martin ND et al. Tracheotomy in ventilated patients with COVID-19. Ann Surg. 2020; 272(1): e30-e32.

17. Yang X, Yu Y, Xu J et al. Clinical course and outcomes of critically ill patients with SARS-CoV-2 pneumonia in Wuhan, China: a single-centered, retrospective, observational study. Lancet Respir Med. 2020; 8 (5): 475-481.

18. Chen J, Fan $\mathrm{H}$, Zhang $\mathrm{L}$ et al. Retrospective analysis of clinical features in 101 death cases with COVID-19. medRxiv. 2020.

19. Chen WQ, Ling WH, Lu CY et al. Which preventive measures might protect health care workers from SARS? BMC Public Health. 2009; 9: 81.

20. Sommer DD, Engels PT, Weitzel EK et al. Recommendations from the CSO-HNS taskforce on performance of tracheotomy during the COVID-19 pandemic. J Otolaryngol Head Neck Surg. 2020; 49(1): 23.

21. Harrison ML, Oxford S. Guidance for Surgical Tracheostomy and Tracheostomy Tube Change during the COVID-19 Pandemic. 2020.

22. Angel L, Kon ZN, Chang SH et al. Novel percutaneous tracheostomy for critically ill patients with COVID-19. Ann Thorac Surg. 2020.

23. Thoracic Surgery Outcomes Research Network, Inc. COVID-19 Guidance for triage of operations for thoracic malignancies: a consensus statement from thoracic surgery outcomes research network. Ann Thorac Surg. 2020.

24. Academy of Medical Royal Colleges. Clinical guide for the management of essential cancer surgery for adults during the coronavirus pandemic. 7 April 2020.

25. Bilkhu R, Viviano A, Saftic I, Billè A. COVID-19: Chest drains with air leak-The Silent 'Super Spreader'? CTSNet, Inc. Dataset. 2020. Available from: https://ctsnet.figshare.com/articles/COVID-19_Chest_ Drains_With_Air_Leak_The_Silent_Super_Spreader_12089130/1. 